\title{
On the acceptability of multiple interrogatives in Italian
}

\author{
Anda Neagu ${ }^{l}$ \\ York University, Toronto, Canada
}

\begin{abstract}
Multiple interrogatives exhibit cross-linguistic variation from a typological point of view. Standard Italian, in particular, is considered to be a language disallowing these constructions, an analysis based on the interaction between whPs and focused constituents in this language. I argue that previous analyses of multiple wh-questions in Italian need to be integrated with novel data, and that these structures are at least marginally acceptable. Specifically, I illustrate data from a preliminary experiment involving acceptability judgements on a 5-point Likert scale that tested whether native Italian speakers consider multiple interrogatives acceptable. While this is still a preliminary investigation, the results indicate that younger native Italian speakers tend to accept these constructions. I suggest that the presence of two whPs within the same clause in Italian can be analyzed as a language contact phenomenon, with English being the source language, in line with the sociolinguistic literature on this topic.
\end{abstract}

Keywords: experimental syntax; Italian; multiple interrogatives; A-bar phenomena.

\section{Introduction}

From a typological point of view, there are many strategies employed by natural languages in the formation of multiple wh-questions. For example, Balkan languages front all wh-phrases (whPs), some Asian languages like Chinese maintain all these elements in situ, and other languages, such as English, adopt a mixed strategy where only one of the wh-words moves while the other stays in situ (cf. Rudin, 1988). Finally, there are languages that have been shown to disallow multiple wh-questions all together, and Italian is one of these.

The literature on A-bar movement that also tackles the topic of multiple and whinterrogatives in Italian (Calabrese, 1984; Rizzi, 1982, 1997; Stoyanova, 2008; Richards, 2014; inter alia) analyzes this language as analogous with languages like Irish, with which it is said to pattern typologically in not accepting multiple interrogatives. However, these analyses of Italian are purely based on the authors' acceptability judgements, an approach that presents some limitations. As a matter of fact, the field of syntax has often been criticized for its lack of an empirical component (e.g., Gibson \& Fedorenko, 2013). Some of the critiques put forward by the detractors of the "traditional" approach to syntax have been the limited poll of participants involved in the data collection, the reduced number of stimuli, and the authors' cognitive biases. While informal acceptability judgement experiments have been shown to be reliable (Sprouse \& Almeida, 2013; Sprouse et al., 2013), especially with smaller samples, formal experiments are

\footnotetext{
${ }^{1}$ Corresponding author: aneagu@yorku.ca
} 
nonetheless a helpful tool in the investigation of syntactic structures and, among other things, in the investigation of the validity of informal methods (cf. Sprouse, 2015).

The aim of this paper is to present the results of a preliminary experiment on multiple interrogatives in Italian that could shed some light on this topic. It will be shown that, in fact, some demographic groups of native Italian speakers tend to accept multiple wh-questions. Moreover, the data suggest that this characteristic of Italian might be relatively new, and, in particular, it might be related to the increasing influence of English on Italian, especially in younger speakers and in speakers with an advanced knowledge of the former language.

\section{Background}

The introduction mentioned that, from a typological point of view, multiple wh-questions are disallowed in certain languages. According to the syntax literature (e.g., Calabrese, 1984; Stoyanova, 2008; Richards, 2014), this group of languages also includes Italian. On the other hand, the sociolinguistic literature (e.g., Berruto, 2017) analyzes Italian multiple interrogatives as a linguistic innovation related to the heavy influence of English over Italian in recent years. The following sections will better illustrate the two approaches.

\subsection{Syntax literature}

According to the grammaticality judgements provided in the previous literature on A-bar phenomena in standard Italian (see Rizzi, 1982; Calabrese, 1984), structures like the one illustrated in (1) are ungrammatical: ${ }^{2}$
(1) * Chi ha
letto $\quad \operatorname{cosa}^{3}$
who have-3SG-PRS read-PPRT what
Who read what?

The judgements coming from these previous works have been used to build theories explaining certain A-bar phenomena in Italian. For instance, Calabrese's (1984) explanation for the informal grammaticality judgements presented in his work relies on considerations concerning multiple information foci. In fact, Calabrese's account is not only based on the elements forming multiple questions, but also on the structures constituting appropriate answers for them, as exemplified in (2):
(2) *Matteo ha letto un manuale, Martina un romanzo Matteo have-3SG-PRS read-PPRT a textbook-MSG Martina a novel-MSG e Luca una fiaba. and Luca a fairytale-FSG
Matteo read a textbook, Martina a novel and Luca a fairytale.

The sentence in (2) includes elements answering both whPs: the preverbal element indicates the reader (who), while the postverbal one is the object undergoing the action (what). In other words, a felicitous answer for a multiple wh-question requires two phrases denoting new information, i.e., two information foci. According to Calabrese (1984), (2) is ungrammatical. The

\footnotetext{
2 The asterisk indicates the informal grammaticality judgements of the cited authors, with which I disagree.

${ }^{3}$ Note that for the object whP the full form would be che cosa, however, for simplification purposes, in this experiment the form cosa was preferred, as it results more natural in informal contexts.
} 


\section{ON THE ACCEPTABILITY OF MULTIPLE INTERROGATIVES IN ITALIAN}

reason, he claims, is that Italian only allows a unique, postverbal information focus, a feature of this language that has also been discussed in other works (cf. for instance Belletti, 2004).

Rizzi (1982), on the other hand, briefly mentions that multiple wh-questions are ungrammatical in Italian, and that this property has consequences for the analysis of wh-islands in this language. However, it is the investigation of A-bar phenomena in Italian from Rizzi (1997) that has consequences for the syntactic analysis of multiple interrogatives. Rizzi (1997), in fact, focuses on the whPs themselves, and on the relationship these establish with other elements in the extended left periphery of the clause. In his article, the author deals with the functional projections forming the CP field and with the elements occupying them. These projections are illustrated in (3):

\section{(3) ForceP $>$ TopP* $>$ FocP $>$ TopP* $>$ FinP}

The projection of interest for the interrogative whPs is FocP, the locus of contrastive focus in Italian ${ }^{4}$ and, in particular, its specifier position. Rizzi (1997) shows that, unlike topics, the focus position is unique. The author also shows that contrastive foci and whPs cannot co-occur, meaning that they compete for the same syntactic position. See, for example, the structure in (4):

(4) *A GIANNI, cosa hai detto, non a Piero? to Gianni what have-2SG-PRS say-PPRT NEG to Piero What did you say to Gianni, not to Piero? $\quad$ (adapted from Rizzi, 1997, p. 291)

Although Rizzi (1997) does not directly deal with multiple wh-questions, it is implied, given the parallel between whPs and contrastive foci, that for the same reasons that there cannot be multiple contrastive foci in Italian, this language also disallows multiple whPs.

None of the analyses presented in this section have used formal experimental methods, and the fact that these theories have been built on informal grammaticality judgements has some undesired consequences. Firstly, since the poll of participants is so limited, this method is unable to grasp how native Italian speakers from different regions, ages, and educational backgrounds perceive multiple interrogatives. It was mentioned, in the introduction, that these constructions have been argued to be a syntactic neologism influenced by English. Consequently, a small number of participants is not ideal for the purpose of understanding how widespread this language change is. In other words, while the authors do not accept these constructions, other speakers, with different demographic characteristics, could consider them acceptable. Secondly, informal methods are less able to capture the gradience of acceptability judgements. Syntactic structures tend to be considered as either grammatical or ungrammatical, without taking into consideration the acceptability of the constructions under analysis, i.e., how appropriate they are in relation to the speaker's performance (Chomsky, 1965). Certain tasks employed by formal experimental methods, on the other hand, such as Likert scale tasks and magnitude estimation tasks, better capture the continuous spectrum that characterizes acceptability judgements. This means that, although the authors' grammaticality judgements can be assumed to be correct, they do not take

\footnotetext{
${ }^{4}$ This refers to the syntactic marking of focused constituents. Italian also allows contrastive focus in a postverbal position if marked by a specific prosodic contour. According to cartographic approaches, even the postverbal contrastive focus occupies spec,FocP in the left periphery, with the rest of the clause undergoing remnant movement. However, this approach presents some issues, some of which are discussed in Samek-Lodovici (2015). I will assume that the postverbal contrastive focus has not moved to the left periphery.
} 
into consideration the degree of acceptability of multiple interrogatives in Italian, and which demographic groups of speakers accept them. Since these constructions seem to be a recent innovation of the Italian language, it is expected that they will be more accepted by younger speakers. Acceptability judgements, then, become a useful tool in the investigation of language change, which is not taken into account in the previous theories on Italian multiple interrogatives.

\subsection{Sociolinguistic literature}

The approaches discussed in the previous section are not necessarily the only analyses we can apply to multiple questions in Italian. Berruto (2017), for instance, argues that multiple interrogatives are a characteristic of neo-standard Italian (Berruto, 1987), and that English has played a crucial role in the increased usage and, consequently, acceptability of these forms. The author analyzes multiple questions as syntactic innovations borrowed from English. Berruto (2017) provides an overview of the analyses put forward in Grasso (2007) and Gandolino (2012): the former indicates that multiple interrogatives are a calque from English employed in the journalistic language; the latter, after carrying out an interview with 122 informants, reaches the conclusion that, even though they are still marginal, multiple wh-questions have become established productive structures in neo-standard Italian.

Berruto (2017) also hypothesizes that the origin of these interrogatives is related to the so called "invisible translations" from English. This term is employed to refer to texts translated from another language into Italian, often by non-professional translators, and whose syntax tends to be modelled on the source language (Grasso, 2007; Ondelli \& Viale, 2010). These invisible translations, which are very popular in journalistic language (but also occur elsewhere), then give rise to syntactic calques from other languages, as in the case of the Italian multiple interrogatives modelled upon their English counterparts. As Berruto (2017) points out, invisible translations are the source of other syntactic properties of Italian that are changing, such as the introduction of the ordinal superlative form, i.e., the usage of ordinal numbers in superlative structures, as well as the placement of new information subjects in a preverbal position, instead of a postverbal one.

The sociolinguistic literature, then, suggests that multiple interrogatives are gaining popularity in Italian. This means that the syntactic theories developed in the ' $80 \mathrm{~s}$ and the ' 90 s to account for the authors' grammaticality judgements were likely the result of the fact that these constructions were less widespread in those decades than they are now. In other words, while the conclusions reached in the past by the syntax literature were well grounded, these past theories need to be expanded in order to account for novel data concerning this ongoing linguistic change. The following sections will discuss these data and how we can account for them.

\section{Experiment}

The experiment was conceived to test whether native Italian speakers consider multiple wh-questions acceptable and, if so, to see which strategies are preferred in the formation of these structures. The results were obtained by creating a factorial design for the stimuli, manipulating the whPs in terms of Superiority Violation (see Chomsky, 1973; 1977; inter alia) and position with respect to the verb (pre- and postverbal position). Participants were asked to provide an acceptability judgement on a 5-point Likert scale and to submit demographic information related to their age, gender, region of provenience, and level of English. Overall, the considerations made by the more recent sociolinguistic literature seem to be on the right track. The following subsections will better outline the experiment and its results. 


\section{ON THE ACCEPTABILITY OF MULTIPLE INTERROGATIVES IN ITALIAN}

\subsection{Design and stimuli}

The experiment has a $2 \times 2$ factorial design, with the independent variables being Superiority Violation and position of the whPs with respect to the verb. This design allows us to investigate the following factors: whether or not the Superiority Violation is met and whether or not the two operators both raise to the right of the verb or only one does. The experiment focused only on argument whPs, specifically on multiple interrogatives involving a subject whP and an object whP. See Table 1 for the design:

Table 1. Experimental design.

\begin{tabular}{|c|c|c|}
\hline Superiority Violation & Position & Sentence \\
\hline No & wh- + V + wh- & $\begin{array}{l}\text { Chi indosserà cosa al suo matrimonio? } \\
\text { who wear-3SG-FUT what to-the POSS wedding } \\
\text { Who will wear what at his/her wedding? }\end{array}$ \\
\hline Yes & wh- $+V+$ wh- & $\begin{array}{l}\text { Cosa indosserà chi al suo matrimonio? } \\
\text { what wear-3SG-FUT who to-the POSS wedding } \\
\text { What will wear who at his/her wedding? }\end{array}$ \\
\hline No & wh- + wh- + V & $\begin{array}{l}\text { Chi cosa indosserà al suo matrimonio? } \\
\text { who what wear-3SG-FUT to-the POSS wedding } \\
\text { Who what will wear at his/her wedding? }\end{array}$ \\
\hline Yes & wh- + wh- + V & $\begin{array}{l}\text { Cosa chi indosserà al suo matrimonio? } \\
\text { what who wear-3sG-FUT to-the POSS wedding } \\
\text { What who will wear at his/her wedding? }\end{array}$ \\
\hline
\end{tabular}

Table 1 shows the four outputs of the design. The structure illustrated in the first row possesses a subject whP that undergoes A-bar movement and lands in the $\mathrm{CP}$ domain, while the object whP stays in situ. The structure below is similar in terms of positions occupied by the two operators with the exception that, in this case, the object whP raises above the subject one, thus violating the Superiority Condition. The last two structures illustrate Balkan-like multiple interrogatives, with both whPs raising into a preverbal position. The positions of the whPs for the latter two interrogatives are, however, pure speculation: it is quite unlikely that they will be considered natural by the participants, thus constituting the ungrammatical baseline for the experiment.

The experiment consisted of 66 items: 16 multiple interrogatives with four versions of each, and 50 fillers. The forms of the stimuli are represented in Table 1, while the fillers were acceptable and unacceptable Italian structures, both declaratives and interrogatives. These items were distributed in a Latin Square design that was created through Ibex Farm, ${ }^{5}$ a website allowing for the creation of online experiments. The participants were able to see only one item per lexicalization and they were presented with all lexicalizations and all conditions. The items composing the experiment were also randomized by Ibex Farm so that the fillers and the stimuli were shuffled for each participant.

\subsection{Procedures}

The questionnaire was created and distributed via Ibex Farm. A 5-point Likert scale task was employed for the experiment, and participants had to decide whether the sentence they were

${ }^{5}$ https://spellout.net/ibexfarm/ 
reading was natural (5), unnatural (1), or somewhere in between. They had to click on a box containing a number from 1 to 5 or to use number keys based on how acceptable a structure sounded to them. An instruction section preceded the rating task, where participants were told that they should consider "natural" those sentences that could be said/heard even in extremely informal contexts. A practice section, consisting of 8 items, preceded the actual experiment and its purpose was to allow participants to familiarize themselves with the task and to use the full range of the scale. Comprehension questions were added to some of the fillers, as well as to two of the practice sentences.

\subsection{Participants}

The number of participants who took the experiment was 131; however, 4 of them were excluded as outliers. They were all native Italian speakers recruited through university Facebook groups and word-of-mouth by family and friends. This resulted in a wide demographic in terms of age, Italian province of origin, and level of English. In terms of gender, participants identified either as female or as male. Nevertheless, the average age was 28 years old, $94.5 \%$ of the speakers were from Northern Italy and $79.5 \%$ of them had either an intermediate or an advanced level of English. For the latter demographic information, they were given the option to choose between null, low, intermediate, or advanced, however, since the within participant variability in the ratings from the participants with a null level of English was significant, those speakers were removed as outliers.

\section{Results}

The results seem to confirm the sociolinguistics literature outlined in section 2: multiple wh-questions are acceptable when compared to the ungrammatical baseline, as long as they do not involve any Superiority Violation. Moreover, the results also indicate that the age of the participants as well as their level of English play a role in the ratings of these constructions.

The figure below summarizes the means of the responses for each condition on a scale from 1 to 5, indicating that only the first condition scores an average above 2.5, i.e., 2.98. This suggests that most participants rate multiple interrogatives higher when they meet the requirements described above in terms of Superiority Violation and position of the whPs. The other conditions possess a very low average, all of them fluctuating between 1 and 1.5.

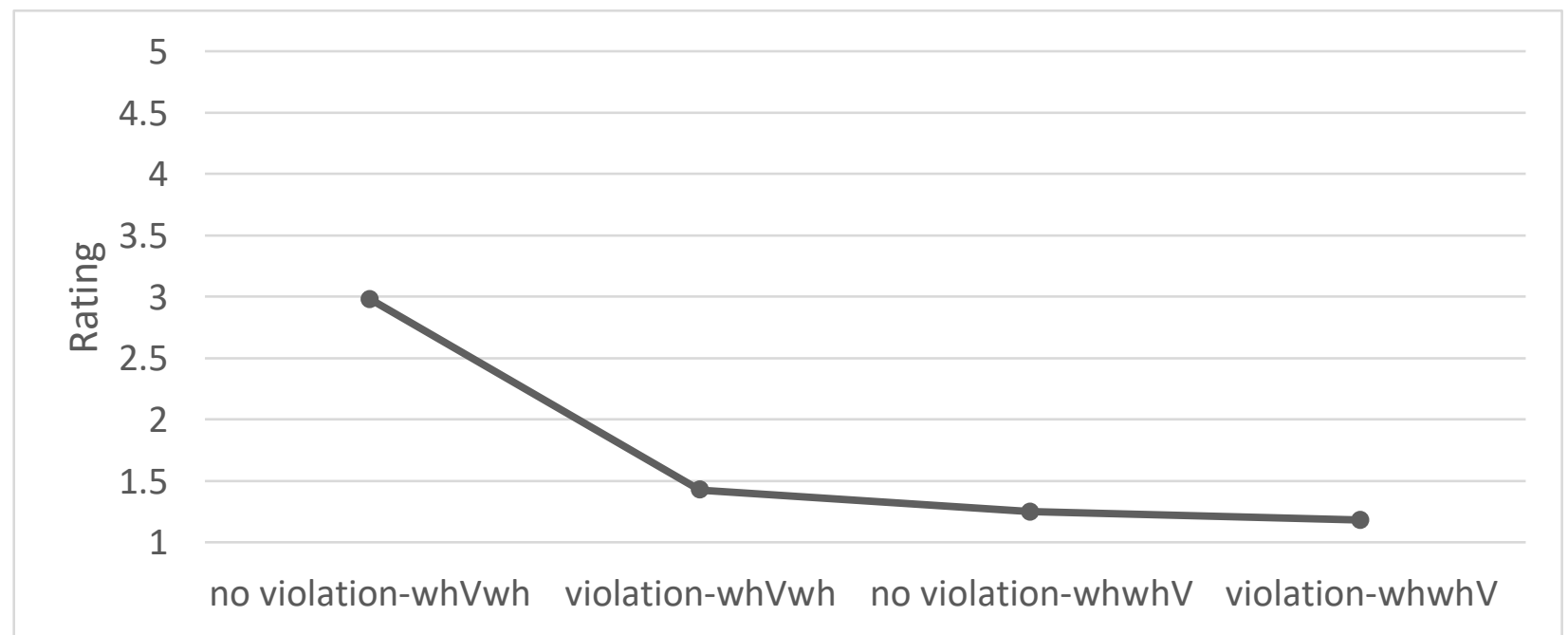

Figure 1. Preferred structure. 


\section{ON THE ACCEPTABILITY OF MULTIPLE INTERROGATIVES IN ITALIAN}

Another factor that seems to play a role in the acceptability judgements is the level of English of the participants. This is illustrated in Table 2 below:

Table 2. Level of English: ANOVA results.

\begin{tabular}{lrrrll}
\hline Cases & Sum of Squares & df & Mean Square & F & p \\
\hline Level of English & 16.459 & 2 & 8.229 & 3.626 & 0.027 \\
\hline Residuals & 1137.033 & 501 & 2.270 & & \\
\hline
\end{tabular}

Since only one type of structure was rated as more acceptable than the others, I ran an ANOVA focusing only on the constructions involving no Superiority Violation, and only one whP in the preverbal position. The purpose of running an ANOVA was to verify the role played by the level of English of the participants in evaluating the multiple interrogatives. As it can be observed in Table 2, the $p$-value for the Level of English is 0.027 , meaning that, although marginally, this is a significant factor. At the same time, if we consider the $p$-values in the Post Hoc comparisons in Table 3, it can be observed that, when comparing the Advanced level of English with the Low level of English, we obtain once again a marginal, but significant value of 0.041 .

Table 3. Level of English: Post Hoc comparisons.

\begin{tabular}{llrlll}
\hline & & Mean Difference & \multicolumn{1}{l}{ SE } & \multicolumn{1}{l}{$t$} & $p_{\text {tukey }}$ \\
\hline Adv & Int & 0.281 & 0.149 & 1.878 & 0.146 \\
\hline & Low & 0.463 & 0.190 & 2.432 & 0.041 \\
\hline Int & Low & 0.182 & 0.201 & 0.907 & 0.636 \\
\hline
\end{tabular}

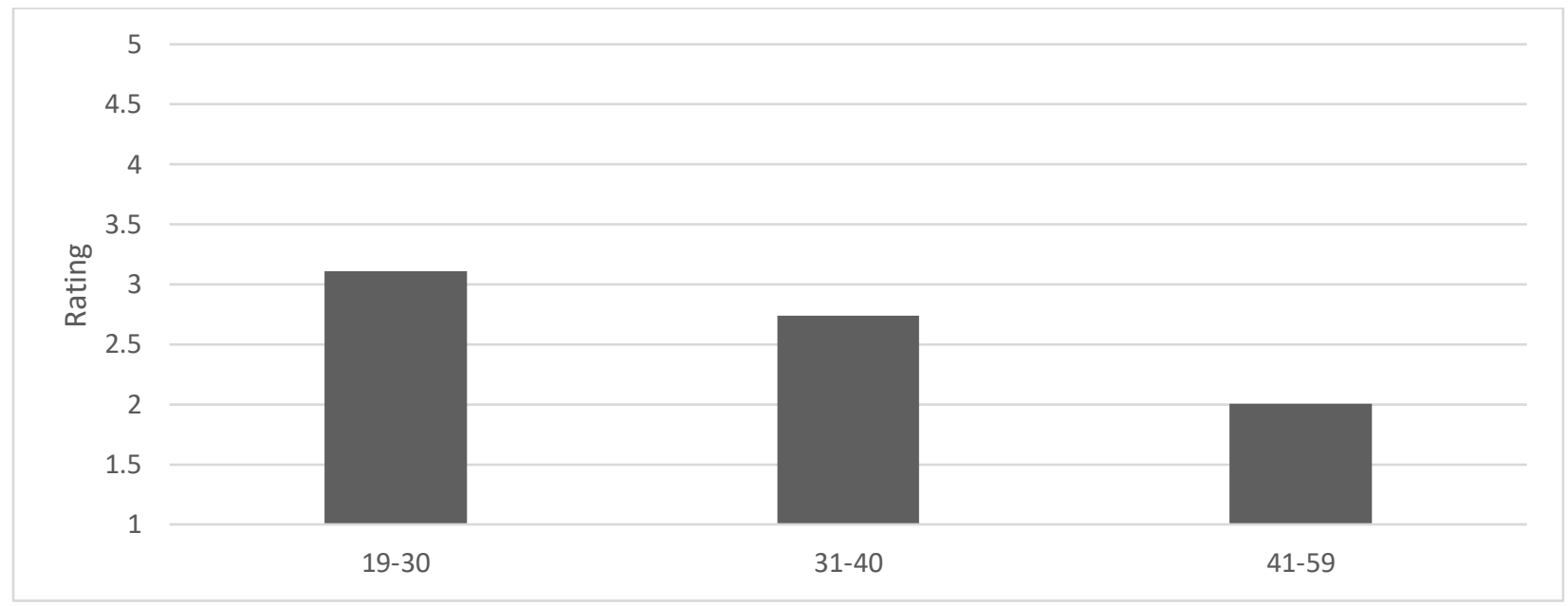

Figure 2. Age.

Moving to the ratings in relation to the age of the participants, Figure 2 illustrates that younger generations tend to rate multiple interrogatives (the more acceptable condition) higher than older generations. The participants were organized in three groups based on their age: I consider the 19-30 years old group to be constituted by those speakers who are likely to have more 
interactions with the English language on a daily basis and to be more sensitive to the introduction of neologisms, including syntactic calques; I consider the 31-40 years old group, on the other hand, to have had heavy interactions with English because of media and arts, but on a lesser level compared to the younger generation; finally, the 41-59 years old group is less likely to have been exposed as much to the English language, thus being less subject to its linguistic influence.

In Figure 2, it can be observed that, indeed, the younger generation is also the one rating multiple interrogatives higher, with an average of 3.1. The middle generation rates these constructions an average of 2.7, while the older generation only rates them an average of 2 .

Finally, in order to verify whether the age and the level of English factors play a similar role in the ratings, I ran a Linear Regression Analysis, whose results are illustrated in Table 4.

Table 4. Linear Regression Analysis.

\begin{tabular}{llrrrrr}
\hline Model & & Unstandardized & Standard Error & Standardized & $t$ & $p$ \\
\hline $\mathrm{H}_{0}$ & (Intercept) & 4.060 & 0.346 & & 11.739 & $<.001$ \\
\hline Age & -0.046 & 0.008 & -0.271 & -6.060 & $<.001$ \\
\hline & & 0.085 & 0.091 & 0.042 & 0.940 & 0.348 \\
& Level of & & & & & \\
\hline
\end{tabular}

As far as the $p$-values are concerned, the one for the age factor is significant, with a value of $<.001$. The level of English, on the other hand, with a value of 0.348, is not significant. This means that age plays a more significant role in the ratings of multiple interrogatives. This, however, does not mean that the level of English is insignificant: the Standardized Coefficient values indicate that, as the age of the participants increases, the ratings decrease; at the same time, as the level of English increases, so do the ratings.

\section{Discussion}

The results outlined in the previous section indicate that Italian seems to be changing with regard to multiple interrogatives. Not all speakers accept them; however, younger generations rate these structures as at least marginally acceptable. While a language-internal change hypothesis should not be excluded, the experimental results suggest that the literature treating these constructions as a calque from English might be on the right track. The following paragraphs will better explore this issue.

Firstly, the structure preferred by the participants was the one involving a preverbal subject whP and a postverbal object whP. This syntactic distribution is the expected one if the language contact hypothesis is correct. Indeed, if Italian multiple interrogatives were introduced in the language as a calque from English, the subject whP would appear in a preverbal position, while the object whP would be postverbal, as illustrated in example (5):

(5) (a) Chi ha mangiato cosa per pranzo?

who have-3SG-PRS eat-PPRT what for lunch-MSG

Who ate what for lunch?

(b) Who ate what for lunch? 


\section{ON THE ACCEPTABILITY OF MULTIPLE INTERROGATIVES IN ITALIAN}

Another confirmation comes from the statistical analysis focusing on the level of English of the participants: the results indicate that the role played by this factor in the ratings of the accepted multiple interrogatives cannot be overlooked. Specifically, they show that speakers with an advanced level of English rate the sentences significantly more acceptable than speakers with a low level of English.

The only statistical results that may seem to go against the language-contact hypothesis come from the Linear Regression Analysis, where it is shown that the age factor is significantly relevant, while the level of English is not. However, these results do not necessarily contradict the sociolinguistic literature (e.g., Grasso, 2007; Berruto, 2017). English started to heavily penetrate into Italian, including its usage by younger generations, starting in the 1970s, an influence that has been growing ever since (Vettorel, 2013). Moreover, the younger group of speakers illustrated in Figure 3 was mostly constituted by university students studying foreign languages at the University of Bergamo and the Ca' Foscari University of Venice. It is likely then, that their interaction with the English language and the influence of the latter over their speech is more prominent than the one exerted over the 31-40, and especially the 41-59 age groups. Therefore, what derives from the statistical analysis is that these younger speakers and speakers with a higher level of English tend to rate the English-type multiple interrogatives higher, thus supporting the hypothesis according to which these constructions are a syntactic innovation that is likely the result of language-contact with English.

If English is indeed the source of this syntactic change, we can account for these constructions by positing that the strong [foc] feature characterizing Italian whPs weakens in multiple interrogatives, as a consequence of language contact (see Serratrice et al., 2004; D'Alessandro, 2020 for more information on the dynamic of language acquisition and language contact, respectively). This can be argued especially for those speakers for whom multiple interrogatives have become productive structures. However, an account for these constructions can also rely on considerations regarding focus positions in Italian. It is often assumed that, in this language, information focus occupies a unique, postverbal position (Calabrese, 1982; Belletti, 2004; inter alia), while contrastive focus raises into the CP field (Rizzi, 1997; Giorgi, 2015; Rizzi \& Bocci, 2017; inter alia). However, Italian also allows for clause-internal focused constituents, as exemplified in (6):

(6) Ho mangiato IL CIOCCOLATO, non le fragole. have-1SG-PRS eat-PPRT the chocolate-MSG NEG the strawberry-FPL I ate CHOCOLATE, not strawberries.

According to cartographic approaches, which deal with the fine-grained mapping of syntactic projections (see Cinque \& Rizzi, 2008), the clause-internal contrastive focus also moves to the left periphery, with the rest of the clause undergoing remnant movement to the same field (Belletti, 2004). I assume, however, following Samek-Lodovici (2015), that focused constituents of the type illustrated in (6) stay in-situ. This means that contrastive focus in Italian can also be licensed post-verbally, not only in FocP in the left periphery, a property observed in other Romance languages such as Romanian or Spanish (see Alboiu, 2004). Given the parallel behavior of contrastive focus and whPs in Italian illustrated in the background section, Italian seems to be already endowed with a position hosting postverbal whPs. The main consequence of the contact with English, then, is the fact that two whPs, instead of one, can be licensed within the same clause. It derives that the presence of two whPs can be accounted for the same way as in English: the 
higher whP overtly raises for feature checking, while the lower one stays in situ and checks its operator feature under Agree.

\section{Conclusions}

This paper has shown that multiple interrogatives are gaining popularity in standard Italian and that English seems to be the source of this syntactic change. The results of the experimental component indicate that the sociolinguistic literature on this topic is on the right track, however, this does not mean that previous syntactic accounts need to be contradicted. This is because the analysis put forward in this paper does not assume that the whPs in Italian possess properties previously unobserved. Rather, it seems that whPs in multiple interrogatives behave differently as a consequence of language contact. In other words, previous accounts need to be broadened in order to encompass novel data resulting from language contact and change.

It is unclear whether multiple interrogatives will eventually become established syntactic structures in Italian, or whether they will never be fully integrated within the language. The experiment described in this paper was only a preliminary investigation that needs to be developed further. The next step is to test the level of acceptability of Italian multiple interrogatives not only in relation to ungrammatical floor conditions, but also in respect to a fully grammatical ceiling condition.

\section{Acknowledgements}

I would like to thank my supervisor, Professor Gabriela Alboiu, for her constructive comments, Brittney O'Neill for her assistance with the statistical analysis, and Matteo Fiorini for his valuable help. I am also very grateful to Professor Keir Moulton for his feedback on the experimental component. Finally, I wish to thank those who attended the 2021 YorkU Graduate Symposium in Linguistics and Applied Linguistics for their useful suggestions. Any errors or oversights contained in the paper are mine alone.

\section{References}

Alboiu, G. (2004). Optionality at the interface: Triggering focus in Romanian. In A. Breitbarth, \& H. van Riemsdijk (Eds.), Triggers (pp. 49-77). Mouton de Gruyter.

Belletti, A. (2004). Aspects of the low IP area. In L. Rizzi (Ed.) The structure of CP and IP: The cartography of syntactic structures, vol. 2 (pp. 16-51). Oxford University Press.

Berruto, G. (1987). Sociolinguistica dell'italiano contemporaneo. Carocci.

Berruto, G. (2017). What is changing in Italian today? Phenomena of restandardization in syntax and morphology: An overview. In M. Cerruti, C. Crocco, \& S. Marzo (Eds.), Towards a new standard: Theoretical and empirical studies on the restandardization of Italian (pp. 31-60). Walter de Gruyter. https://doi.org/10.1515/9781614518839-002

Calabrese, A. (1984). Multiple questions and focus in Italian. In W. de Geest, \& Y. Putseys (Eds.), Sentential complementation (pp. 67-74). Foris.

Cinque, G., \& Rizzi, L. (2008). The cartography of syntactic structures. CISCL Working Papers, 2, pp. 1-17.

Chomsky, N. (1965). Aspects of the theory of syntax. The MIT Press.

Chomsky, N. (1973). Conditions on transformations. In S. Anderson, \& P. Kiparsky (Eds.) $A$ festschrift for Morris Halle (pp. 232-286). Holt, Rinehart, and Winston.

Chomsky, N. (1977). On wh-movement. In P. W. Culicover, T. Wasow, \& A. Akmajian (Eds.), Formal syntax. Academic Press.

D'Alessandro, R. (2020). Syntactic change in contact: Romance. Annual Review of Linguistics, 7(23), pp. 1- 23. 


\section{ON THE ACCEPTABILITY OF MULTIPLE INTERROGATIVES IN ITALIAN}

Gibson, E., \& Fedorenko, E. (2013). The need for quantitative methods in syntax and semantics research. Language and Cognitive Processes, 28, pp. 88-124.

Giorgi, A. (2015). Discourse and the syntax of the left periphery. In J. Bayer, R. Hinterhölzl, \& Trotzke, A. (Eds.) Discourse-oriented syntax (pp. 229-250). John Benjamins Publishing Company.

Grasso, D. (2007). Innovazioni sintattiche in italiano alla luce della nozione di calco. PhD Thesis.

Ondelli, S., \& Viale, M. (2010). L'assetto dell'italiano delle traduzioni in un corpus giornalistico: Aspetti qualitativi e quantitativi, Rivista internazionale di tecnica della traduzione, 12, pp. $1-62$.

Richards, N. (2014). A-bar movement. In A. Carnie, D. Siddiqi, \& Y. Sato (Eds.), Routledge handbook of syntax (pp. 167-191). Routledge.

Rizzi, L. (1982). Issues in Italian syntax. De Gruyter.

Rizzi, L. (1997). The fine structure of the left periphery. In L. Haegeman (Ed.), Elements of grammar (pp. 281-337). Kluwer.

Rizzi, L., \& Bocci, G. (2017). Left periphery of the clause: Primarily illustrated for Italian. In M. Everaert, H. C. van Riemsdijk (Eds.), The Wiley Blackwell companion to syntax, second edition (pp. 1-30). Wiley Blackwell.

Rudin, C. (1988). On multiple questions and multiple wh-fronting. In Natural Language and Linguistic Theory, 6, pp. 455-501.

Samek-Lodovici, V. (2015). The interaction of focus, givenness, and prosody: A study of Italian clause structure. Oxford University Press.

Serratrice, L., Sorace, A., \& Paoli, S. (2004). Crosslinguistic influence at the syntax-pragmatics interface: Subjects and objects in English-Italian bilingual and monolingual acquisition. Bilingualism: Language and Cognition, 7(3), pp. 183-205.

Sprouse, J., Almeida, D. (2013). The empirical status of data in syntax: A reply to Gibson and Fedorenko. Language and cognitive processes, 28, pp. 222-228.

Sprouse, J., Schütze, C. T., \& Almeida, D. (2013). A comparison of informal and formal acceptability judgements using a random sample from Linguistic Inquiry 2001-2010. Lingua, 134, pp. 219-248.

Sprouse, J. (2015). Three open questions in experimental syntax. Linguistics Vanguard, 1(1), pp. 89-100. https://doi.org/10.1515/lingvan-2014-1012

Stoyanova, M. (2008). Unique focus: Languages without multiple wh-questions. John Benjamins Publishing Company.

Vettorel, P. (2013). English in Italian advertising. World Englishes, 32(2), pp. 261-278. 